\title{
Los ch'oles y la tierra: redefinición intergeneracional en tiempos de crisis y migración campesina
}

\section{Ch'ol People and the Land: Intergenerational Redefinition in Times of Crisis and Peasant Migration}

\author{
Adriana Corroy Moral \\ El Colegio de la Frontera Sur, Unidad San Cristóbal de Las Casas, Chiapas, México
}

\begin{abstract}
Resumen: En este artículo tratamos de describir y analizar las relaciones de las familias ch'oles con la tierra. Ubicamos por lo menos dos grupos generacionales distintos, padres e hijos. Nuestro método de investigación es cualitativo, se centra en narrativas de los sujetos participantes y revisión bibliográfica. Los resultados obtenidos nos revelan que en un contexto de crisis y migración en el campo se generan cambios intrafamiliares que resignifican la relación de los ch'oles con la tierra; mientras que para los padres que permanecen en las comunidades de origen, la tierra posee un valor vital para la sobrevivencia, para los hijos jóvenes adultos, que luego de migrar se han integrado a contextos urbanos o son migrantes agrícolas temporales para el mercado internacional pasa a la evocación, a la memoria, el descanso o el ocio. Sin duda, esto sugiere un quiebre de la relación de trabajo con la tierra para cada una de esas dos generaciones. Consideramos que este trabajo contribuye al debate sobre temas que se entrecruzan como pueblos indígenas, tenencia de la tierra y migración.
\end{abstract}

Palabras clave: Tenencia de la tierra, poder, conflictos, narrativas, jóvenes.

AвSTRACT: In this article we seek to describe and analyze the relationship between Ch'ol families and land, focusing on two distinct generational groups, parents and children. Our research method is qualitative, centered on the narratives of our participant subjects and literature review. The results obtained reveal that within a context of crisis and migration from the countryside, intra-familial changes are occurring and resignifying the relationship between Ch'ol people and land. For parents who remain in their home communities the land continues to be vital to their survival, while 
for young adult children who have integrated into urban contexts or are temporary agricultural migrants for the international market, the land becomes associated with evocation, memory, rest or leisure. Undoubtedly, this suggests a break in the working relationship with the land for each of these generations. This paper will contribute to discuss intersecting issues such as indigenous peoples, land tenure and migration.

KEYwORDs: Land tenure, power, conflict, narratives, youth.

RECEPCIÓN: 25 de abril de 2019.

ACEPTACIÓN: 21 de junio de 2019.

DOI: https://doi.org/10.19130/iifl.ecm.55.2020.0010

\section{Introducción}

El objetivo de este trabajo consiste en describir y analizar las modificaciones relacionadas con la tierra en ejidos ch'oles, a partir de las vivencias de los sujetos participantes en la investigación, considerando dos generaciones. Para ello, se documentan algunas etapas en el tiempo histórico, hasta llegar a los cambios actuales. Nos acercamos a la realidad investigada a través de la narrativa de Juan, un padre de familia ch'ol, y entrevistas periféricas a madres, hijas e hijos de la región. Los resultados obtenidos nos indican que la dificultad de acceso a la tierra para las nuevas generaciones ha ocasionado modificaciones intergeneracionales e intrafamiliares en las localidades de origen, las cuales muestran la pérdida del valor de la tierra y revelan un incremento en la migración de la juventud para buscar otras opciones de subsistencia. Todo lo anterior sugiere un rompimiento generacional entre padres e hijos, y uno más en los cambios históricos, que van en sentido contrario al enraizamiento de los ch'oles con la tierra.

Los ch'oles, ${ }^{1}$ como muchos grupos indígenas de Chiapas, han pasado por una historia de despojos relacionada con la búsqueda de tierra para subsistir. La tierra y su valor simbólico ${ }^{2}$ forman parte de la estructura de vida de este pueblo, valor que se ha modificado, entre otras cosas, con el "paradigma de la propiedad privada”. ${ }^{3}$ Estos cambios en la relación con la tierra y su valor han sido atribui-

\footnotetext{
${ }^{1}$ Se denomina ch'oles a los hablantes del idioma ch'ol, el cual es una variante lingüística de las agrupaciones de la familia maya (Instituto Nacional de Lenguas Indígenas, 2008).

${ }^{2}$ De acuerdo con Bourdieu (2011), el valor simbólico de un bien está determinado por el despliegue de los capitales que un agente posee: 1) capital económico: propiedades y fuentes de ingreso; 2 ) capital social: conjunto de recursos ligados a una red de relaciones; 3) capital cultural: éste puede ser incorporado como las cualidades cognitivas, objetivado a través de instrumentos u objetos, e institucionalizado por títulos y reconocimientos. Los tres tipos de capitales determinan el capital simbólico.

${ }^{3}$ El paradigma de la propiedad privada lleva implícito una relación de poder sobre las personas y las cosas, que se unifican en la sociedad capitalista, marca una relación desigual entre propietarios y desposeídos, que ahora son doblemente desposeídos, de su tierra como capital y de su fuerza de trabajo (Arriola, 2002), además de alterar sus otros capitales sociales y culturales.
} 
dos, inicialmente, a las relaciones desiguales — de raza y de clase - mediadas por la actividad laboral en el campo, entre los colonizadores y los pobladores originarios de la región chiapaneca; posteriormente, a las relaciones complejas entre los ch'oles y el Estado como promotor de la comercialización de tierras a inmigrantes extranjeros; y, finalmente, al mismo Estado como mediador en la recuperación y redistribución de la tierra para los indígenas a través del ejido.

La búsqueda de tierra de los ch'oles, que pareciera que termina con la obtención de una propiedad "legal", con un valor económico y simbólico "recuperado", sería suficiente para su autosuficiencia alimentaria. Sin embargo, los pueblos indígenas de Chiapas viven actualmente excluidos y marginados, con un ejido en crisis e inmersos en problemas estructurales profundos, como la pobreza, el hambre y la migración (Villafuerte, 2015).

Para conocer cómo se están viviendo las modificaciones relacionadas con la tierra en el ejido, nos acercamos desde un nivel microsocial a las familias ch'oles a través de la investigación narrativa. La narrativa nos posibilita el acceso a la experiencia desde la voz de las y los participantes en la investigación. Con ésta, podemos además establecer temporalidades, causalidades y relaciones, constituyéndose como una vía de acción y denuncia para el sujeto. La narrativa se convierte en un lugar de encuentro (Schongut, 2015: 127), permitiendo reestablecer la relación sujeto-objeto de las perspectivas de investigación tradicionales desde un punto de vista que permite ser, estar y participar del mundo. A decir de Haraway (1988: 581), las narrativas son un conocimiento situado; en esta óptica no existe una sola verdad y una realidad, sino que detrás subyace el hecho de que todo conocimiento es parcial y contingente, y que, además, existen múltiples conocimientos sobre un mismo fenómeno.

A través de la teoría de los campos de Bourdieu (2011), analizamos las relaciones intrafamiliares de poder. Nuestro campo está constituido por la familia ch'ol, como un espacio físico y social, determinado por las relaciones intrafamiliares. En él se encuentran en juego los capitales (social, cultural, económico, simbólico) relacionados con la tierra, mismos que son utilizados como un arma o como apuesta en las relaciones al interior de la familia.

En la primera parte de este artículo mencionaremos algunas de las modificaciones históricas que consideramos sirven para ejemplificar los cambios en la relación de los ch'oles con la tierra. Para ello utilizamos también lo que dicen diferentes autores sobre la historia de Chiapas, específicamente de la región ch'ol. Estas modificaciones se dirigen particularmente al tema de la tierra como "propiedad" y su valor simbólico, que puede incluir la actividad laboral en el campo, las relaciones de poder, la familia y sus desplazamientos. La segunda parte se encuentra dividida en tres secciones: primero se abordarán las localidades de estudio (Masojá Grande y Teanijá, en Tila y Salto de Agua, Chiapas) y la metodología de trabajo; enseguida, el análisis de los datos, donde incluimos la narrativa de Juan, un padre de familia ch'ol que, desde su voz, nos relata sus experiencias; y, finalmente, se presentará el análisis de la narrativa y las conclusiones. 


\section{Los ch'oles: una historia de búsqueda de tierra para sembrar}

Durante el siglo xIv los ch'oles se desplazaban por la región conocida como la media luna cholana. ${ }^{4}$ En ese territorio buscaban en la tierra su alimento para poder sobrevivir. Se dedicaban principalmente a cultivar, cazar y pescar. La gran mayoría dependían del cultivo de la milpa: ch'ol significa "milpa", y de ahí proviene la denominación que pusieron los conquistadores a sus hablantes. La milpa es un sistema prehispánico de producción agrícola, donde además del maíz, se cultivaba frijol y calabaza (García de León, 1979: 261). El proceso de siembra y cosecha dependía adicionalmente de rituales relacionados con los que se consideraban los favores de la tierra, el dios de la lluvia y los cuatro cargadores del mundo (De Vos, 2010: 32). En la búsqueda de tierras fértiles para alimentarse, se movilizaban y asentaban temporalmente en pequeñas aldeas de acuerdo con sus períodos de siembra, utilizando el sistema tradicional maya de roza-tumba y quema. ${ }^{5}$ Los asentamientos poblacionales eran pequeños y dispersos, cada familia vivía cerca de su milpa y sus muertos, donde formaban pequeñas localidades, para luego desplazarse en comunidad (De Vos, 2010: 32).

El uso de la tierra con un sentido de "comunalidad" se basaba en la toma de decisiones de la aldea en su conjunto. Se utilizaba para la agricultura, la caza y la pesca, de acuerdo con las necesidades de consumo familiar; ${ }^{6}$ así, cada aldea tenía un uso restringido de su territorio (Breton, 1988; García de León, 1979). Las familias vivían en casas con dos habitaciones: la recámara y la cocina, donde se llevaban a cabo las reuniones familiares bajo un esquema de control parental y familias nucleares.

Este tipo de relación con la tierra se modificó con la llegada de los conquistadores de la península ibérica durante los siglos xv y xvı. Los colonizadores desconocieron las prácticas comunales y se establecieron como los nuevos "propietarios" de las tierras, legalizando de esta manera su despojo, marcando con ello el inicio del paradigma de la propiedad privada, de tal manera que pasaron de ser

\footnotetext{
${ }^{4}$ La media luna cholana se refiere al territorio que abarcaba desde el oriente de Tabasco, el norte de Chiapas, la selva lacandona, el sur de Petén y Belice, hasta el oriente de Guatemala y Honduras. Estaba habitado por personas del mismo origen linguiístico maya clásico, perteneciente a la rama occidental y a la gran subdivisión cholana. Los dos componentes del cholano mayor son el tseltalano (tsetal y tsotzil) y el cholano (ch'ol, chontal y chorti) (Alejos y Martínez, 2007; Josserand y Hopkins, 2006).

${ }^{5}$ El RTQ es un sistema agrícola cíclico rotacional de cultivo mesoamericano; consiste en cortar la vegetación (roza), luego los árboles (tumba), dejando tocones de los mismos, picar las ramas, abrir guardarraya y quemar (quema) para sembrar. Se realiza generalmente en temporada de secas, de esta manera la tierra está preparada para las primeras lluvias y la siembra (Hernández, Baltazar y Levy, 1995).

${ }^{6}$ Nos referimos a la familia como el espacio donde se reproducen inicialmente las visiones particulares del mundo. Un universo microsocial complejo, desigual y no siempre homogéneo y solidario. Se encuentra formado por varios integrantes, por lo que, necesariamente, se cruzan factores como la edad o el género en relaciones dispares generacionales entre padres e hijos, sus relaciones son diversas y no están representadas como un único modelo familiar (Blanco, 2011: 144).
} 
"libres" y autosuficientes a ser deudores de los encomenderos de la Corona Real del ahora llamado Estado español, para poder cultivar la tierra. Detrás de este cambio "natural" en la propiedad de la tierra subyace la invalidación de "otras"7 formas de su manejo, además de la invisibilización del sentido de pertenencia social, cultural y ritual indígena (Merino, 2014: 947).

De esta manera, inició todo un proceso de reorganización del territorio. Los ch'oles tenían "derechos" para trabajar la tierra pero los españoles eran los propietarios; así empezó la reducción y formación de pueblos. Los ch'oles fueron condicionados a establecerse en poblados y en viviendas designadas por los colonizadores, cultivando la milpa en pequeñas parcelas, pagando con el fruto de su trabajo a los caciques y encomenderos de la Corona Real para asegurar su subsistencia. Con ello fueron estableciéndose de manera violenta relaciones desiguales entre los nuevos propietarios y los despojados, con una posición subordinada y tributaria respecto al manejo y la actividad laboral en el campo (García de León, 1979: 268).

Con el fruto de su trabajo, los indígenas también sostenían al clero, dedicado a congregarlos y adoctrinarlos en la religión católica. Existe un registro de la región ch'ol del año 1564, cuando fray Pedro Lorenzo de la Nada agrupó a los ch'oles, que hasta entonces vivían dispersos, en los llamados pueblos de indios, que hoy son los poblados de Tila, Tumbalá y Palenque, que durante la colonia se convirtieron en las tres cabeceras principales de la región (Breton, 1988: 298).

Por otra parte, muchos escapaban, huyendo de las calamidades naturales, los tributos injustos, los castigos de parte de los jueces de milpa y diversas perturbaciones sociales, tratando de evadir el control social, tributario y evangelizador de los conquistadores (Breton, 1988; De Vos, 2010). Los ch'oles de Salto de Agua fueron pobladores que escaparon de Tila y Tumbalá buscando tierras y huyendo de las cargas tributarias, las hambrunas y las enfermedades. Salto de Agua se fundó en 1794, y se estableció como un puerto comercial cuya ubicación en las márgenes del río Tulijá permitía transportar en barcos la mercancía que traían de Tila y Tumbalá a Palenque, Tabasco y Campeche (Alejos y Martínez, 2007).

No fue sino hasta el siglo xIx, tras muchos años de lucha y denuncias de abusos contra los indígenas por parte de algunos personajes como fray Bartolomé de las Casas, algunos particulares y encomenderos, que los ch'oles recuperan el derecho a trabajar sus tierras y el uso comunal de las mismas a cambio de la protección jurídica de la Corona. La lógica de las prácticas feudales de la Corona española ayudó a proteger los derechos aldeanos de "propiedad comunal campesina" (Gall, 1999: 60). Entre los siglos xvi y xvil existe un vacío de información de lo que pasó en la región. Según Viqueira (2011: 11-12), los ch'oles entraron de lleno a una

\footnotetext{
${ }^{7}$ Desde la descolonización se reconocen las "otras" formas de colonización, del poder, saber y hacer, así como la necesidad de recuperar el "otro"conocimiento, el de los excluidos y marginados (Quijano, 1993; Mignolo, 2000; Grosfoguel, 2013).
} 
etapa de migraciones en la búsqueda de trabajo y tierras, hubo despoblamiento de aldeas por muertes y enfermedades en la zona ch'ol; fue en esta época que los campesinos fueron desapegándose de sus tierras ancestrales.

Otro cambio importante en la relación de los ch'oles con la tierra se realizó entre 1876 y 1911 durante el régimen de Porfirio Díaz, período en el que se establecieron leyes que modificaron la estructura agraria del país. A través de dichas leyes, se autorizó a colonos extranjeros invertir en tierras "baldías", ${ }^{8}$ propiedad del Estado, para el cultivo de café, henequén y hule, esto con la finalidad de generar divisas y empleos a los campesinos de la región (Andrade, 2015). La época porfirista marcó un rompimiento en la tenencia de la tierra de los campesinos. En este proceso se sustituye el autoconsumo por el consumo industrial, se promueve la inmigración, el cambio en la propiedad y la organización agraria (Guerrero, 2016: 251).

El cultivo de café en Chiapas fue promovido por políticas federales y estatales, modificando nuevamente el uso de la tierra y el modo de vida ch'ol. Grandes latifundios de tierra de la región ch'ol fueron vendidos a inmigrantes europeos, desconociendo los derechos de posesión de los indígenas, los terrenos de las comunidades sujetas al comercio, y despojando nuevamente a los ch'oles de sus tierras ancestrales (Alejos, 1995: 326). Adicionalmente, pasaron a formar parte de otro sistema de explotación, la servidumbre por deudas, característica de las fincas cafetaleras (Gall, 1999: 63). El cultivo de café y su comercialización fueron integrados a las prácticas cotidianas, al mismo tiempo que algunos se dedicaban a la milpa para subsistir.

Familias enteras se vieron forzadas a desplazarse, eran atraídas de los pueblos y localidades para trabajar y vivir en las fincas, o bien, algunos de sus miembros se separaban del resto de la familia en la búsqueda de un trabajo asalariado como peones endeudados (mozos o acasillados), ${ }^{9}$ trabajadores, arrendatarios, sirvientes, jornaleros temporales o trabajadores de construcción (Toledo, 2013), todo esto en un sistema de capitalismo basado en relaciones sociales laborales de explotación y dominación (García de León, 1979). Los ch'oles fueron incorporados al mercado mundial. La comercialización del café y su exportación robusteció la economía local y nacional. El sistema económico promovido para la región

\footnotetext{
${ }^{8}$ De Vos (1984: 38), menciona que el gobierno mexicano, a través de las Leyes de la Colonización (1824 y 1830), facilitó la entrega gratuita de terrenos baldíos; éstos eran aquellos que no habían sido otorgados por "reales mercedes", por lo que no tenían títulos de propiedad ni límites oficiales y pertenecían a la nación; la repartición de estas tierras a particulares y compañías se trató de hacer efectiva con la Ley de Ocupación y Enajenación de Terrenos Baldíos (1863); sin embargo, no fue sino hasta 1875, con la Ley General sobre Colonización, en el gobierno de Lerdo de Tejada, que se celebraron los primeros contratos, retomándose con modificaciones en 1883, con el régimen de Díaz.

${ }^{9}$ De acuerdo con Toledo (2013), el mozo acasillado se diferenciaba de los otros por la relación laboral de dependencia económica hacia el patrón. La vivienda, parcela, gastos para actividades rituales de producción y salud eran proporcionados por el patrón en calidad de préstamo, reproduciendo y acrecentando las deudas morales y económicas de los trabajadores.
} 
favorecía a los empresarios, de tal forma que, entre 1879 y 1885 , existían en el departamento de Palenque 113 fincas, y para 1909, ya había 6,800 propiedades rurales (Andrade, 2015: 54). Así, los pobladores indígenas fueron forzados a vivir como trabajadores agrícolas en condiciones de extrema pobreza y servidumbre (Alejos, 1999: 432).

\section{Antecedentes agrarios de las localidades de estudio}

Entre 1910 y 1920, con la Revolución Mexicana, y después de muchos años de lucha, los ch'oles se liberaron al lograr expulsar a los patrones de las fincas. El ejido aparece formalmente instituido en la legislación mexicana el 6 de enero de 1915; nace como un instrumento de recuperación de las tierras que habían sido otorgadas a extranjeros, ladinos y rancheros de la región (Alejos, 1999; Imberton, 2002), con la idea de "restituir la propiedad comunal" de los pueblos indígenas.

La Constitución de 1917 incluyó el reparto de tierras en su Artículo 27, estableciendo que las tierras, entonces liberadas, eran propiedad de la nación, y se entregaban en usufructo a una corporación civil, el ejido o la comunidad. Éste tuvo a partir de entonces una personalidad jurídica, sujeta a restricciones como las siguientes: la tierra debía ser cultivada por el titular; no debería mantenerse ociosa ni venderse ni alquilarse ni usarse como garantía; podía ser heredada por un sucesor escogido por el poseedor, entre muchas otras.

Entre 1930 y 1939, en el período cardenista, se entregaron en el estado de Chiapas 290,354 hectáreas a más de 20,000 campesinos (Andrade, 2015). Con el ejido, los ch'oles recuperaron parte de sus tierras ancestrales y se constituyeron en sus derechohabientes. Fue en esta época que los pobladores de las localidades de estudio iniciaron los trámites para la obtención de su dotación ejidal. Los pobladores de Teanijá iniciaron el proceso en 1939, pero no fue sino hasta 1954 que les fueron concedidas 473 hectáreas de terrenos nacionales. Dichas hectáreas fueron consideradas como montes laborables; de ellas, 20 se utilizaron para la zona urbana del poblado (Diario Oficial de la Federación, 1969). Se concedieron 10 hectáreas a 25 pobladores de la región, que fueron heredadas a los hijos de los primeros ejidatarios, mismas que, hasta el día de hoy, son trabajadas para subsistir. ${ }^{10}$ Por otra parte, Masojá Grande se fundó en 1940 y se amplió en 1958. En el Diario Oficial de la Federación (1973), se documenta la dotación de 3,130 hectáreas de cerriles a los pobladores de Masojá y Jonichtle, beneficiando a 258 individuos con parcelas de 10 hectáreas para cada uno; el resto serían utilizadas para uso colectivo de ambas comunidades.

\footnotetext{
${ }^{10}$ Esta información surgió en las entrevistas que realizamos durante nuestras estancias en Teanijá.
} 
Para el pueblo ch'ol, la tierra, históricamente y hasta el día de hoy, constituye una fuente de conflictos, principalmente agrarios, ya que se mezclan intereses culturales, políticos, sociales y económicos como los relacionados con la repoblación de localidades, los despojos e invasiones de tierra, la sobreposición de límites ejidales, los desplazamientos forzados, la fragmentación de las parcelas, entre muchas otras irregularidades (Aguilar, 2014: 76-86). Adicionalmente, los conflictos se relacionan con la falta de buenas tierras, los escasos recursos económicos destinados para la producción y las tecnologías, así como con las diferencias que existen entre los mismos pobladores. Estos hechos favorecen la migración de los jóvenes y los desplazamientos de las familias en la búsqueda de nuevas oportunidades económicas y educativas para huir del hambre y la pobreza (Alejos, 1995: 425).

Con la Reforma Constitucional de 1992, como un agregado neoliberal, la nación dejó de ser la propietaria jurídica de las tierras sociales y su propiedad pasó a los ejidos marcando el inicio de la propiedad privada. El Estado transfirió la propiedad ejidal a los núcleos ejidales. La asamblea ejidal, conformada por todos los ejidatarios, pasó a ser la autoridad definitoria del uso, disfrute y comercialización de la tierra; los campesinos ahora son libres de manejar su "desarrollo" (Kourí, 2015).

Sin embargo, de acuerdo a Harvey (2005), la liberalización del mercado de las tierras, con las modificaciones de la Reforma de 1992, se hizo para fomentar la penetración de relaciones capitalistas de producción. De esta manera, se utilizan las leyes para "legalizar" este tipo de despojos, que no son fortuitos, ya que van acompañados de otras formas de dominación basadas en la desigualdad, la raza y el género (Quijano, 1993). El ejido fue creado como un mecanismo gubernamental para que los campesinos tuvieran tierras de cultivo, pudieran producir sus alimentos básicos, obtener seguridad alimentaria y autonomía; sin embargo, los campesinos son, hoy en día, los más pobres y excluidos del país (Warman, 2003).

Con la modificación del Artículo 27 constitucional se finalizó el reparto agrario y se firmó el Tratado de Libre Comercio (TLC) provocando una crisis en el campo al recortarse los subsidios y programas al mismo. Autores como López y Peláez (2013) concluyen que con la implantación de políticas neoliberales en el país se provocaron cambios en el mercado de trabajo, el cual no genera empleos adecuados ni las condiciones de bienestar mínimas para subsistir, especialmente en las localidades indígenas, obligándolos a emigrar; Chiapas pasó de ser un estado de atracción de inmigrantes relacionados con la economía de las plantaciones a finales del siglo xIx, a uno de expulsión de personas en la actualidad.

Todo lo anterior ha provocado cambios en la relación de los ch'oles con la tierra, sobre todo en la actividad laboral de los agricultores, la reconfiguración de los espacios rurales y las modificaciones en el modo de vida de los campesinos. Un ejemplo lo constituye la desagrarización, en la que se reconocen alteraciones en cuatro aspectos fundamentales: 1) una inevitable reducción de las actividades 
agropecuarias; 2) el incremento de la pluriactividad de las unidades domésticas;

3) la creciente captación de ingresos en los hogares a partir de la migración, y

4) una disminución de los hogares campesinos en el medio rural (Carton, 2009). Estas transformaciones ponen en evidencia las alteraciones en las relaciones de los ch'oles con la tierra y su efecto al interior de las familias. Como ejemplo podemos mencionar las limitaciones del ejido y la actividad campesina como fuente de subsistencia de las familias de este pueblo.

La historia de los ch'oles refleja las diferentes etapas y movilizaciones en la búsqueda de tierra para sembrar. Han pasado de tener la tierra con un sentido de propiedad comunal y desplazarse por sus territorios ancestrales a ser dotados de tierra en la época de la Colonia para garantizar su reproducción como tributarios y fuerza de trabajo de la Corona española; posteriormente, han tenido que modificar su condición laboral con los finqueros, además de transitar de sus cultivos tradicionales al cultivo del café; han tenido que luchar por recuperar sus tierras para asentarse y ser "propietarios" de una parcela y finalmente vivir en un ejido. Ahora se enfrentan a otros conflictos, los relacionados con mantener la tierra y hacer lo que saben hacer para sobrevivir, cultivar.

Con base en lo anterior, y como respuesta a la inquietud de lo que está sucediendo ahora con la tierra en los ejidos, nos acercamos a padres, madres, hijas e hijos ch'oles para conocer, desde sus experiencias y su voz, las percepciones actuales en su relación con la tierra y cómo las manejan los integrantes de algunas familias de Teanijá y Masojá Grande.

\section{Localidades de estudio}

Teanijá es una pequeña comunidad de casas dispersas en pequeños lomeríos ubicada en el municipio de Salto de Agua, Chiapas (Figura 1). Su nombre significa, en ch'ol, "agua de cal", y se encuentra en la ribera de un río que lleva el mismo nombre. Es una localidad rural donde todos sus habitantes hablan ch'ol; para llegar ahí, se recorren $40 \mathrm{~km}$ desde la cabecera municipal. Cuenta con una escuela primaria multigrado, una iglesia católica y algunas calles de terracería. La cantidad de habitantes en Teanijá en 2010 era de 314, ocupando 53 viviendas. El $46 \%$ de la población en ese año era analfabeta y el $67 \%$ de 15 años y más tenía únicamente la educación primaria terminada. El índice de marginación era de $83.02 \%$, considerado muy alto por la Secretaría de Desarrollo Social (2010a). ${ }^{11}$

${ }^{11}$ En adelante SEDESOL. 


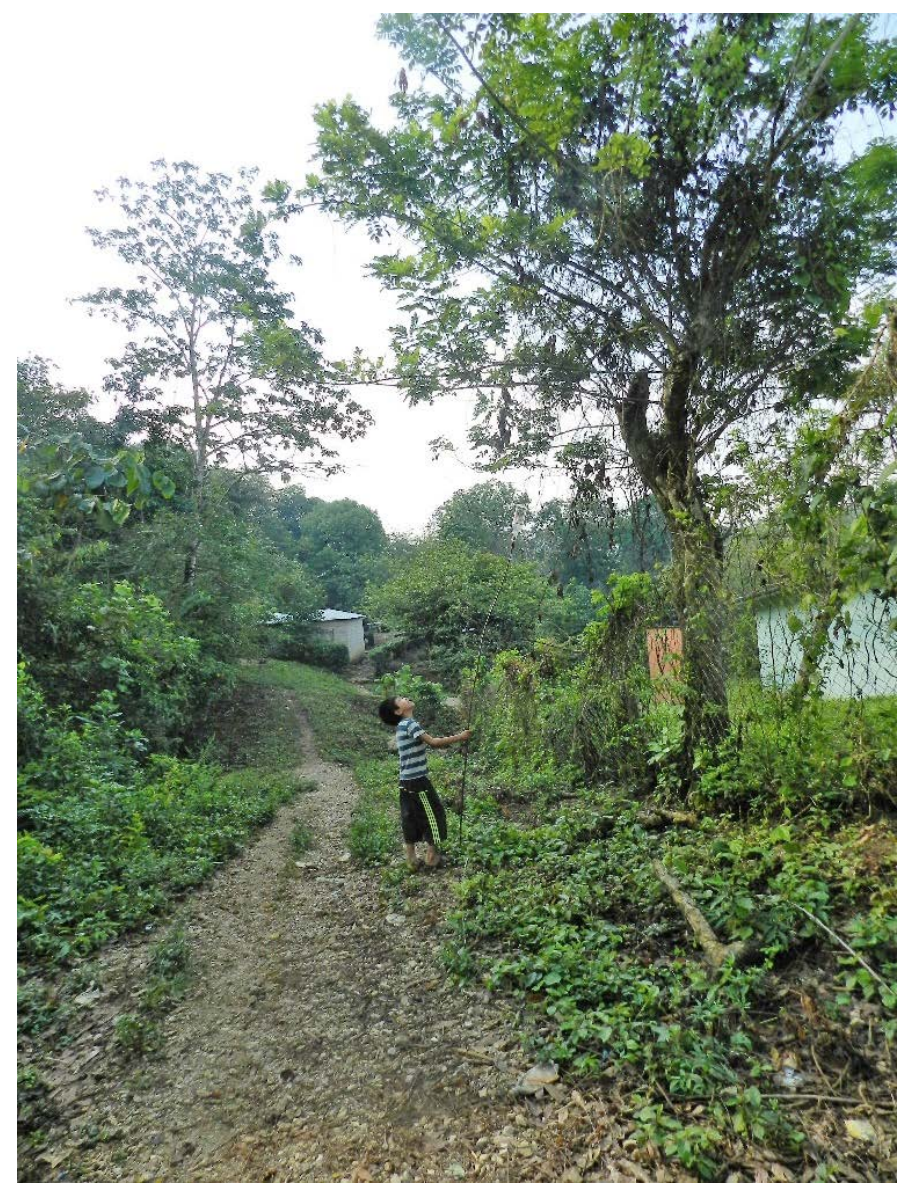

Figura 1. Las casas de Teanijá están separadas unas de otras por veredas y abundante vegetación.

En la imagen aparece Lucio atrapando chicharras; con una rama larga y una botella de plástico a manera de embudo las captura; estos insectos forman parte de la alimentación de los habitantes de la localidad (Fotografía de Adriana Corroy, 2017).

Masojá Grande pertenece al municipio de Tila y se encuentra ubicado a $23 \mathrm{~km}$ de la cabecera municipal (Figura 2). Para llegar a la localidad, se toma la carretera de Tila a Limar y, posteriormente, una desviación de $5 \mathrm{~km}$ de terracería; en sus linderos se ven las milpas y potreros en pequeñas montañas.

La población se agrupa en torno al río Masojá, que se deriva del nombre de un pez, aunque algunos pobladores dicen que significa "agua con frialdad" en ch'ol. La población total en 2010, era de 479 habitantes, los cuales ocupaban 101 viviendas. En la localidad existen tres escuelas de educación básica: preescolar, primaria multigrado y una telesecundaria. El $87 \%$ de la población habla ch'ol y el $15 \%$ es analfabeta. El grado de marginación municipal es muy alto, el $94.3 \%$ de la 


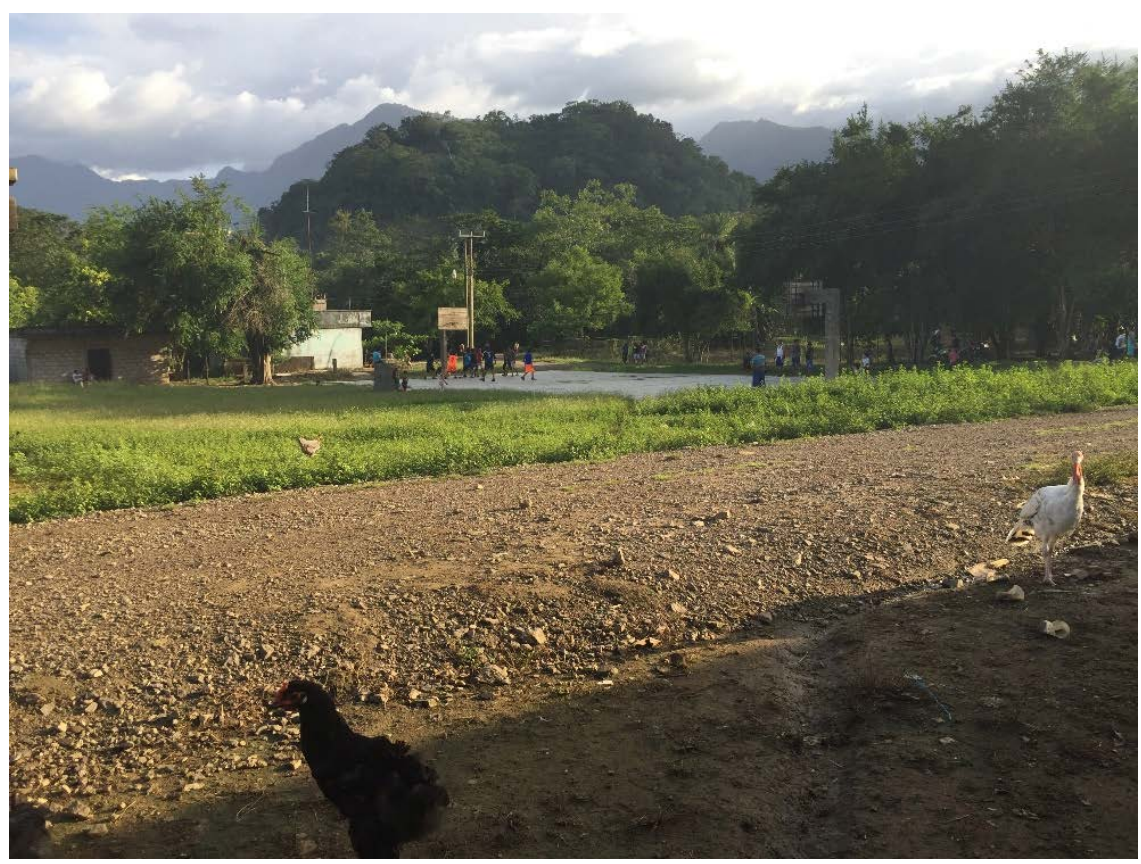

Figura 2. Masojá Grande con sus casas dispersas y calles de terracería. Por las tardes, algunas mujeres y hombres se reúnen a jugar basquetbol en la cancha de la localidad (Fotografía de Adriana Corroy, 2018).

población es considerada pobre y un $69.3 \%$ de los pobladores se encontraban en pobreza extrema en ese año según la SEDESOL (2010b).

\section{Metodología de trabajo}

El objetivo inicial de las primeras estancias en las localidades fue conocer el modo de vida del pueblo ch'ol a través de sus conflictos. Con la convivencia, surgieron el tema de la tierra y de la emigración de sus hijos como generadores de conflictos al interior de las familias (Denzin y Lincoln, 2011). Observamos que la mayoría de las familias de ambas localidades tienen hijas e hijos emigrantes. Con base en lo anterior, analizamos la relación con la tierra al interior de dichas familias, donde la migración se revela como un síntoma que atraviesa la vida de las personas y trastoca las relaciones familiares.

Adicionalmente, para explorar y profundizar en puntos de vista de diferentes actores y así establecer interrelaciones familiares, se aplicaron entrevistas exhaustivas - estructuradas y semiestructuradas - a madres y padres de familia de ambas comunidades: tres padres y tres madres con un promedio de edad de 50 años. De igual modo, se aplicaron entrevistas formales e informales a seis hijas 
e hijos, con un rango de 15 a 40 años de edad. Todos eran hablantes ch'oles; únicamente tres de las mujeres entrevistadas no hablaban español, para lo que se contó con el apoyo de traductores originarios de las localidades. De la misma manera, realizamos observación participante en las comunidades de estudio; estas experiencias fueron plasmadas en diarios de campo.

Los entrevistados han tenido experiencias migratorias desde dos diferentes posiciones: los que se van y los que se quedan en el lugar de origen. Esto nos permitió conocer el punto de vista de madres y padres que permanecen en su lugar de origen y desde ahí ven a sus hijos partir, como Juan, el protagonista de la narrativa. Asimismo, se integran testimonios de los hijos que permanecen y algunos que emigraron. Lo anterior permitió profundizar en sus subjetividades, sus conflictos y los cambios intrafamiliares a los que se enfrentan en su relación con la tierra.

\section{Análisis de los datos}

La construcción de la narrativa es un trabajo analítico. La narrativa de Juan, que en este artículo se expone, se creó a partir de cuatro estancias en Teanijá y una en Masojá Grande, Tila, en períodos de una a dos semanas. Adicionalmente, se realizaron nueve estancias cortas de dos a tres días en ambas localidades, durante un año y medio (entre 2016 y 2018). Dichas estancias permitieron interactuar con Juan, madres, hijos e hijas de diferentes familias en sus espacios y actividades de la vida cotidiana: el acompañamiento a la milpa, la siembra y tapiscado del maíz, la recolección de leña, así como largas pláticas en la hamaca, convivencias en los días de fiesta, rezos y actividades de cocina, observación del trabajo en casa y recorridos de traspatio. Esta narrativa se escribió y se reescribió tratando de identificar los elementos relacionados con la tierra, organizados cronológicamente para después compartirlos con la persona entrevistada y volver a escribir (Creswell, 2005). A partir de este análisis y de los relatos construimos la narrativa principal, seleccionamos los subtemas de una manera secuencial para entender el tema de la tierra en ambas localidades y cómo éste atraviesa el interior de las familias y las personas participantes de Masojá Grande y Teanijá.

\section{Narrativa de Juan: iSe me fue Juanito!}

Soy Juan, originario de Teanijá, en Salto de Agua, Chiapas. Soy campesino y me dedico a trabajar la tierra. No tengo otro trabajo, vivo de cultivar maíz en la milpa; también cazo algunos animales, como tepezcuintles y sereques para comer. Además del maíz, siembro frijol, camote, yuca y algunas hierbas, como la yerbamora y el chapay, pues éstas crecen de manera natural en la región. Mi papá me enseñó a sembrar la milpa y a saber cuándo la debo sembrar, por 
ejemplo, la milpa se siembra entre el 20 y el 30 de abril; en esta fecha siembro también la yuca y el plátano. Con mi papá aprendí que cuando es luna llena, debo sembrar camote, cebolla y macal, a diferencia del maíz y el frijol, que se siembra en cualquier luna.

Tengo 40 años, soy padre de siete hijos: cuatro de ellos son hombres y tres mujeres. Mis tres hijos más grandes ya se fueron. Dos de ellos trabajan en Cancún, los dos son chefs de restaurantes de un hotel; al principio eran meseros y poco a poco fueron aprendiendo a hacer comida. Mi hija más grande se fue primero y se llevó a los hermanos, uno de mis hijos ya se casó allá, también ella está casada, su esposo es de Quintana Roo y viven en Cancún todos. Ellos vienen una vez al año a visitarme; en diciembre, para el año nuevo, cuando vienen, matamos un puerco o pollos, esos los cría mi mujer todo el año y nos los comemos con mis hijos en las fiestas. Ya tengo dos nietos, un niño y una niña.

Cuando se fue María, mi hija, todo cambió, me puse muy triste. Cuando, después, se fue Hilario, lo sentí más, pues él era como Juanito, mi hijo de 18 años; Hilario me acompañaba a la milpa, ahora todo eso lo hace Juanito. Hilario decía que ya no quería trabajar conmigo, ya no me quería acompañar, y por eso se fue. Yo me sentí muy solo y triste, pues ya no tenía quién me acompañara a la milpa.

Yo, en la edad de Hilario, nunca me quise ir, tengo derechos con mi parcela y, si me iba, los podía perder. Además, yo nunca me hubiera ido, a mí me gusta estar aquí, ésta es mi casa. Aquí los jóvenes ya casi todos se van, por eso ya casi no hay gente en la comunidad; se van a Cancún, a Playa del Carmen, a Ciudad del Carmen, a Villahermosa y a Mérida. No se van a Estados Unidos, se van aquí en México. La mayoría de los que se van, no regresan, sólo vienen a visitar a sus papás. Mis hijos le cuentan a su mamá —a mí no me dicen nada— que para ellos es difícil trabajar allá porque a veces no encuentran trabajo, o no les pagan bien, muchas veces no les alcanza ni para comer. Ahora ya mis hijos están bien, ya los tres que se fueron tienen casa, y me siento bien, porque ellos ya están bien.

Aquí en Teanijá se van por igual hombres y mujeres. La primera mujer que se fue era mi prima. Ella se tuvo que ir porque su papá se fue con otra mujer de Berlín, un ejido cercano, su mamá se murió y la dejó sola con sus cuatro hermanos y con su abuela. Se fue a trabajar primero a Villahermosa, después a Tuxtla y después a Tlaxcala, y les mandaba dinero a sus hermanos; se fue como en el año 1992 y nunca volvió, ahora vive en Tlaxcala, ahí se casó y ahí se quedó, ya tiene hijos y familia allá. Después de ella, los demás jóvenes empezaron a salir, algunos al lugar donde ella se fue, después a otros lugares más cerca de aquí. Las mujeres se van a Villahermosa o a Cancún a ayudar en las casas o en la limpieza de los hoteles, los hombres trabajan de meseros o albañiles.

La vida en el pueblo ha cambiado, ahora el pueblo se siente triste, ya no hay gente. Los que se van ya no hacen los rituales, ya no se acuerdan, ya no están acostumbrados a trabajar. A María, mi hija, ya se le olvidó trabajar, donde ella está ya no hace nada; aquí hace tortillas, hace pozol; allá, todo lo compra, ya no 
hace nada, sólo compra tortillas y compra el pozol. Cuando viene aquí, le gusta hacerlo, pero se cansa, se quema las manos y dice que es un duro trabajo, ya no es lo mismo.

A mí no me gusta Cancún, ya fui a visitar a mis hijos tres veces. Hace mucho calor y uno tiene que estar encerrado todo el día. Aquí, si me aburro, me voy al campo a trabajar y respirar aire fresco; allá, sólo en la casa podemos estar. Mis hijos me mandan dinero a veces, no mucho y no siempre, pero ayudan. Ellos me dicen que algún día van a regresar a Teanijá.

Juanito se fue a Cancún y se regresó porque no le gustó, dice que tenía que viajar todos los días en un autobús y no le gustó, trabajaba de albañil. Ahora, él tiene 18 años y se fue a trabajar a Sonora a recoger espárragos. Vino un familiar y les contó que trabajaba allá y que pagaban bien y lo convenció. Estoy muy triste porque se fue, él era mi compañero de trabajo, pero va a regresar en tres meses, cuando termine su contrato, y se irá de nuevo si lo vuelven a contratar. Le dijeron que le van a pagar $\$ 200$ pesos diarios, y que después le van a incrementar el salario y él estaba muy contento; Juanito ya está listo para trabajar, yo estoy contento si él está contento, para mí no es un problema que mis hijos salgan a trabajar. Con Juanito se fueron ocho primos, primero les pidieron sus papeles, acta de nacimiento y su credencial de elector.

Extraño mucho a Juanito, a mí me gustaría que mis hijos no se fueran, que no se les olviden las cosas, pero yo les enseñé a trabajar, ellos saben trabajar. Ahora en la milpa me ayuda Mauricio. Mauricio es mi primo y no tiene trabajo. Él vive solo con su hermano y el hermano no trabaja porque está enfermo, se emborracha y ya lo han macheteado dos veces; así ayudo a Mauricio porque está enfermo, toma lembal ${ }^{12}$ todo el día y, cuando no lo hace, le dan temblores.

Ana también se quiere ir, ella tiene 16 años y su hermana se la quiere llevar a trabajar. Ana ya está en edad de casarse, vino un muchacho a pedirla, pero mi mujer y yo le dijimos que no, pues era muy loco. Ana no quiere casarse y por eso se quiere ir. Nosotros nos casamos a los 15 años y siempre hemos vivido aquí en Teanijá. Si se va Ana, me pondré muy triste, ya sólo me quedaré con la que está en la secundaria y con Sebastián, que está en $4^{0}$ grado de primaria, yo no quiero que se vaya.

Los conflictos a los que nos enfrentamos como ejidatarios son generalmente a la invasión de parcelas, al robo de leña, pollos, maíz y de vacas. También tenemos problemas entre los militantes de los partidos políticos, que son del Partido Verde y del Partido de la Revolución Democrática. Aquí en Teanijá ha ayudado que los ejidatarios somos los hijos de los ejidatarios fundadores, nadie ha vendido y seguimos siendo las mismas familias quienes trabajamos las tierras y casi todos somos católicos.

\footnotetext{
${ }^{12}$ Aguardiente de caña de azúcar.
} 


\section{Narrativas}

Como jefe de familia, y al interior de su hogar, Juan fomenta las relaciones intrafamiliares y construye su capital social. Él es el propietario de la parcela donde siembra, tiene su vivienda y un potrero donde engorda al ganado, lo que constituye su capital económico. Enseñó a sus hijos a trabajar en la milpa de acuerdo con sus costumbres y tradiciones, mismas que fueron heredadas de sus padres, como nos comentó en la narrativa (Figura 3); éstas forman parte de su capital cultural. Toda la familia está relacionada con la tierra. El despliegue, que no siempre es racional, de todos sus capitales (social, cultural y económico) constituye su capital simbólico y representa su fuente de poder (Bourdieu, 2011).

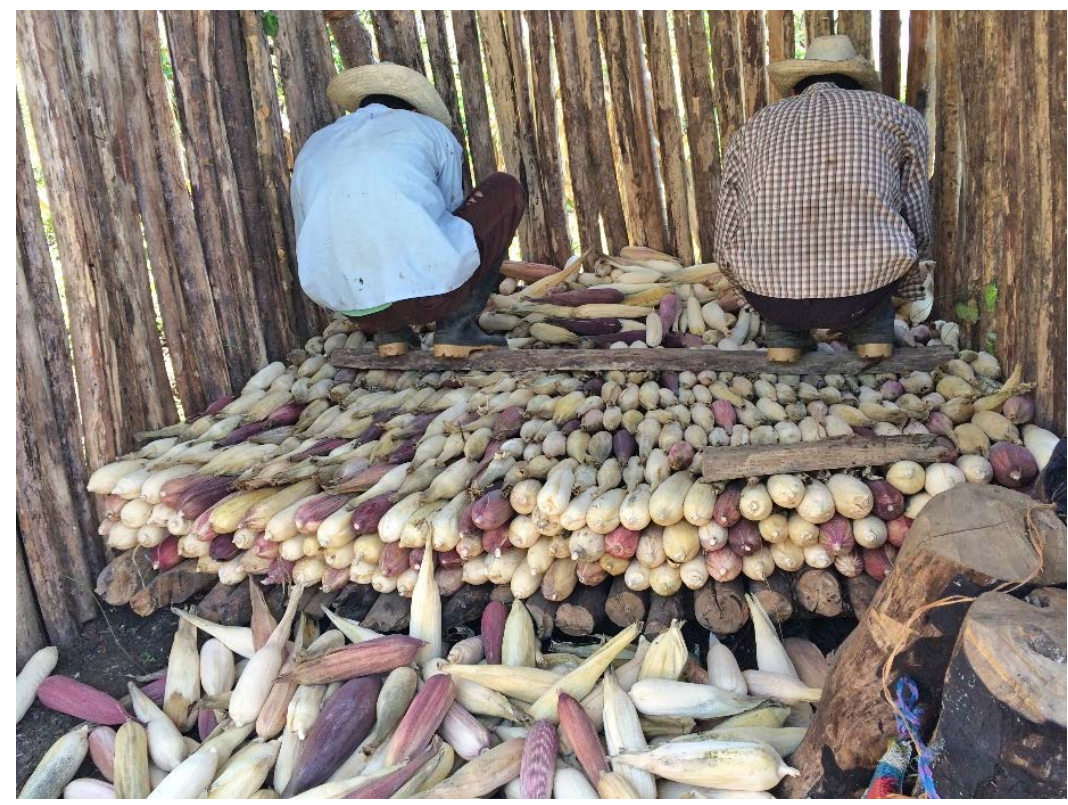

Figura 3. Juan y su hermano acomodando el maíz en la troje que tienen en la milpa, como les enseñó su padre. Las mazorcas deben de estar organizadas de tal manera que queden bien apretadas para evitar que se las coman las tuzas (Fotografía de Adriana Corroy, 2017).

Juan nos relató su experiencia acerca de los cambios en las relaciones entre él y sus hijos varones, determinadas por la edad de los hijos en cuanto a la asignación del trabajo en la parcela y la mano de obra en el cultivo de la milpa. ${ }^{13}$ Esta forma de trabajo solidario es parte de la estructura familiar en las relaciones

13 Según Gutiérrez (2017), ser joven entre los ch'oles consiste en pasar de una categoría de ser niños a ser personas casadas; ésta se encuentra determinada por el trabajo comunitario, la potencia y jerarquía social, y varía de acuerdo al género. 
padre-hijo de los ch'oles; un ejemplo lo constituye la relación entre padre-hijo mayor en el proceso de acompañamiento y trabajo en la siembra.

Los hijos mayores de edad acompañaban al padre a la milpa, a cazar, a pescar y a la crianza del ganado. Juan ejerció su poder de padre en la construcción de los capitales de sus hijos, que participan en todas las actividades laborales que su padre les enseñó. En este intercambio, Juan invirtió en sus hijos sus capitales, por ejemplo, sus conocimientos, y les proporcionó casa y alimentos. Los hijos, al casarse, viven con la mujer y sus propios hijos en la casa de Juan, por lo que se encuentran subordinados a su poder, ya que dependen de su padre para trabajar a cambio de la alimentación y la vivienda. Tal poder se rompe hasta que el padre decide heredarle una parte de la tierra, el hijo logra independizarse, construye su casa, cultiva su parcela y así logra subsistir por sí mismo.

Cuando Hilario, su hijo mayor, emigró en busca de otro tipo de trabajo, ajeno a la agricultura, alteró la relación familiar. Juan, quien manifestaba su poder a través de su capital simbólico, lo pierde. La relación padre-hijo se rompe y, al interior de la familia, las relaciones se alteran. Adicionalmente, el hijo se llevó con él los capitales invertidos por Juan.

Estos roles familiares establecidos, y lo que se espera de ellos como padres e hijos al interior de las familias, se rompen con la migración. Desde la teoría de Bourdieu (2011), este habitus ${ }^{14}$ es objetivado generacionalmente — por ejemplo, en el uso de la tierra para sembrar y trabajar en la milpa-y asociado con lo subjetivo: tal es el caso de la percepción simbólica que tienen de la tierra o los rituales de siembra mencionados por Juan en la narrativa; éstos son estructurales en los agentes y se hacen cuerpo, son estructurantes (Bourdieu y Wacquant, 1995: 25).

Ello se percibe en la narrativa de Juan y en el conflicto intrafamiliar e intergeneracional que le generan estos cambios, sobre todo por la confrontación que existe entre lo que ha aprendido generacionalmente de su trabajo tradicional contra el de sus hijos, quienes con la emigración ya se dedican a otras actividades, que son diferentes a las tradicionales y que están dirigidas al mercado. Por ejemplo, las actividades primarias modificadas, como las de su hijo menor, Juanito, que se dedica al cultivo de espárragos en compañías multinacionales en el norte de México; o las de sus otros hijos, que se dedican a actividades secundarias o terciarias, como la albañilería o la hotelería. Juan tuvo que ver cómo lo que su padre le había enseñado en las prácticas tradicionales — por ejemplo, cuándo y qué sembrar de acuerdo al ciclo lunar; cómo cazar y cómo pescar-, se fue perdiendo con la partida de su hijo. No sólo perdió sus capitales, como el

\footnotetext{
${ }^{14}$ El habitus es un sistema socialmente constituido de disposiciones estructuradas y estructurantes que es adquirido mediante la práctica y está siempre orientado hacia funciones prácticas. El habitus permite analizar cómo la práctica tiene un sentido estructural para el agente (acción consciente) y un sentido estructurante (que es parte del sujeto mismo, muchas veces inconsciente). Depende de la historia individual y colectiva, así como de la capacidad creadora y generadora del agente; en este sentido, el agente es creador y mediador, como sujeto encarnado, de las estructuras que se tienden a reproducir (Bourdieu y Wacquant, 1995).
} 
apoyo con la mano de obra, sino a su compañero, quedándose con un sentimiento de tristeza y soledad.

Ante estas circunstancias, que le son ajenas a Juan y confrontan el habitus de su estructura familiar, se ve obligado a modificarlo, adaptarse y establecer nuevas disposiciones o funciones prácticas (Bourdieu, 2011), para seguir trabajando la tierra sin la ayuda de los hijos que emigraron. El trabajo de Juan, como un mecanismo para poder subsistir en familia, continúa con los hijos que permanecen en su lugar de origen. Juan recurre a la búsqueda de un sustituto y un nuevo compañero para trabajar en la milpa, generalmente es el hijo mayor que sigue en la escala de edad. Si este último emigra, empieza el proceso nuevamente con el siguiente hijo, y cuando ya no tiene a nadie más al interior de la familia, contrata mano de obra; el puesto de trabajo vacante es generalmente ocupado por algún familiar, a quien le tiene que pagar el día laborado, modificando con ello su capital económico.

Cuando los padres son mayores de edad y todos sus hijos emigraron, recurren, como en el caso de Miguel —otro padre de familia de Masojá Grande— a "rentar" la tierra. Este tipo de acuerdos y reglas no escritas se emplean generalmente con un pariente u otro miembro de la localidad como una estrategia para conservar el poder sobre la tierra y su manejo. La tierra se renta para sembrar milpa o como potrero para engordar ganado (Figura 4); Miguel comentó: "ya no tengo apoyo de mis hijos, por eso rento mi potrero a mil pesos mensuales por ocho animales; se lo rento a mi primo". Su primo es un ganadero de la localidad, del cual, ahora, Miguel depende económicamente. Se puede decir que esta estrategia, que parece que termina en rentar la tierra, constituye una pérdida en cadena, hasta que la tierra ya no tiene el mismo valor simbólico e intrafamiliar, y por eso se "renta".

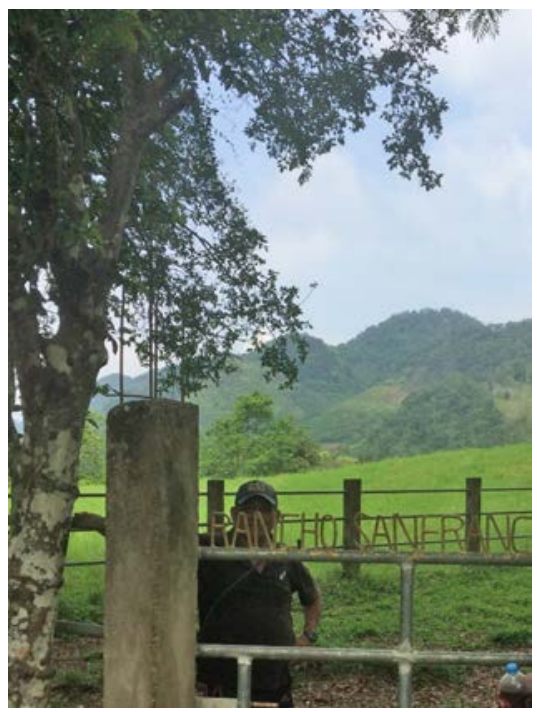

Figura 4. La renta de tierras y la formación de ranchos dentro del ejido Masojá Grande (Fotografía de Adriana Corroy, 2018). 
El cambio de actividad laboral, de sembrar la milpa a rentar la tierra a un agente externo, rompe las relaciones entre padres e hijos y rompe también con el vínculo generacional de los padres con la tierra y su cultivo. Juan y Miguel ya no cuentan con la mano de obra de sus hijos para trabajar la tierra, alterando con ello su estructura familiar; menos hijos, menos poder. Ante esto, los padres propietarios se ven obligados a entrar al mercado de tierras. Con los hijos expulsados por un sistema estructural como la pobreza - que constituye una forma de violencia simbólica (Bourdieu, 2011) ${ }^{15}$ y que los obliga a buscar empleo fuera de sus localidades de origen-, los padres recurren a la estrategia de rentar la tierra a quien tiene la posibilidad de pagarla y así entran en una relación de dependencia económica.

Los cambios en la propiedad de la tierra y la liberación para el comercio de la misma producen procesos de despojo que son necesarios para la acumulación de capital. Según Harvey (2005: 113), la violencia y el despojo para la acumulación de capital forman parte de un sistema capitalista que se nutre de ello. El despojo histórico de las tierras a las comunidades indígenas arranca su vinculación con el territorio para integrarlos a un sistema global interconectado. Por otra parte, para los hijos de Juan que emigraron, el valor de la tierra también se modificó, ya no constituye más un capital simbólico. Para ellos, ya no existe la necesidad de subsistencia con ella, no tiene más un valor cultural, social ni económico. Su relacionalidad con la naturaleza cambia, estos valores fueron transformados por otros, los del mercado.

De acuerdo con Bourdieu (2011), las estructuras objetivas se construyen en las trayectorias históricas de los agentes y se hacen cuerpo, se incorporan en la percepción, los valores, los pensamientos y las acciones de éstos. Como ejemplo, podemos mencionar la búsqueda de un trabajo asalariado para subsistir en otras condiciones y en otro espacio social. Esto ya lo hacían las familias ch'oles con los finqueros (Alejos, 1995; García de León, 1979; Toledo, 2013), reproduciendo ambos grupos sociales las relaciones laborales de dominación. Los hijos de Juan, al emigrar y entrar al trabajo asalariado, se incorporaron a otro espacio social, donde reproducen el patrón en la relación dominante-dominado al integrarse al trabajo asalariado del mercado, donde son susceptibles a reproducir mecanismos históricos, tales como la explotación laboral, la división vertical del trabajo, la penetración de otras ideologías y la fragmentación social-familiar, además de la marginación "laboral".

Un ejemplo lo constituye Juanito, el hijo de Juan, que ahora trabaja en los cultivos de espárragos, lo mismo que Prudencio; ambos laboran actualmente en el estado de Sonora, y Prudencio así lo percibió:

\footnotetext{
${ }^{15}$ La violencia simbólica es la que se da en las relaciones de poder y en el intercambio de bienes materiales, "esa violencia que arranca sumisiones que ni siquiera se perciben como tales apoyándose en unas 'expectativas' colectivas, en unas creencias socialmente inculcadas” (Bourdieu, 2011: 15).
} 
Los contratos no se cumplen en las barracas, existe mucha discriminación; todos los trabajadores son indígenas de Oaxaca, Chiapas, Veracruz y Guerrero, algunos llegan con sus padres y a veces solos, algunos no saben hablar español y les cuesta mucho trabajo comunicarse y defenderse; muchas veces son menores de edad y para llegar ahí, y que los contraten, prestan las actas de nacimiento.

Prudencio se siente acorralado por esta situación, ya que en su comunidad no encuentra empleo:

Tengo que trabajar por temporadas e irme, porque no tengo otra opción, en octubre empieza la temporada del cultivo de espárragos, nos pagan $\$ 15$ pesos por caja; en diciembre, febrero, mayo y junio trabajo en la pizca de uva o melón. Ésta la pagan por la cantidad de surcos que recogemos, trabajamos por cuadrillas de ocho a 10 personas y un cuadrillero que nos vigila.

Juan, en su narrativa, percibe además modificaciones entre los ritmos y ciclos vitales de sus hijas e hijos, que ya son otros. Como los mencionados por él acerca de María, su hija, o lo que nos dicen algunos padres, como Miguel, en Masojá Grande:

Los hijos, cuando regresan, ya no quieren trabajar y se les olvida todo lo que nosotros les enseñamos. Trabajan en otra cosa, pero no la tierra, ya se les hace un trabajo pesado; ya no hacen los rituales, ya no se acuerdan.

Tanto para Juan como para Miguel, desde su posición de padres, representa un conflicto intersubjetivo el saber que a sus hijos se les olvidó todo. Miguel menciona los cambios que percibe entre los ritmos de vida de sus hijos emigrantes y qué tan diferentes son a los suyos:

Cuando vienen a visitarme, son puro dormir, ya no me acompañan a trabajar; se levantan a las 9 de la mañana, no es igual, como nosotros que nos levantamos a las 4 de la mañana; desde los 19 y 20 años de edad, me levantaba a las 2 de la mañana y a las $4: 30$ salíamos a trabajar.

Según Bourdieu (2011), estas modificaciones en el habitus son generadas y generadoras. Allí se refleja tanto la enajenación como la inclusión de una superestructura en los agentes que penetra, se mantiene en ellos y se encarna, generando y creando otras con un sentido práctico de sobrevivencia. También se expresan de manera subjetiva en el dolor y la tristeza que causa la separación entre padres e hijos, como lo manifiesta Amelia, la esposa de Juan:

Me pongo muy feliz cuando regresan, se siente uno bien, tranquilo, pero cuando regresan a trabajar ya me pongo triste de nuevo, nada más llegan un ratito y se van. Ellos ya no se acostumbran a estar aquí, ya no quieren trabajar en el campo, cambia mucho su comportamiento. Sus patrones ya no los dejan regresar porque ya 
están muy acostumbrados a trabajar con los hijos de sus patrones. Y cuando vienen aquí, vienen a divertirse, a tomar trago, ya no quieren trabajar. Se van a pasear y a tomar trago en Limar y nada más vienen un rato en la casa, ya no convivimos bien.

Juan relata en su narrativa cómo sus hijas también modifican las actividades que les enseñó su madre (Figura 5). Cuando emigran, las actividades de las hijas mayores recaen en la que le sigue en escala de edad. Las hijas emigrantes trabajan de empleadas domésticas y/o en la limpieza de hoteles en Villahermosa y Cancún. Regresan esporádicamente a visitar cuando tienen vacaciones, contribuyen económicamente a la familia cuando les alcanza. La mayoría de las mujeres que emigran no regresan a vivir en sus comunidades de origen, como María, la hija de Juan, modificando así su estructura familiar, lo que causa dolor y tristeza a los padres.

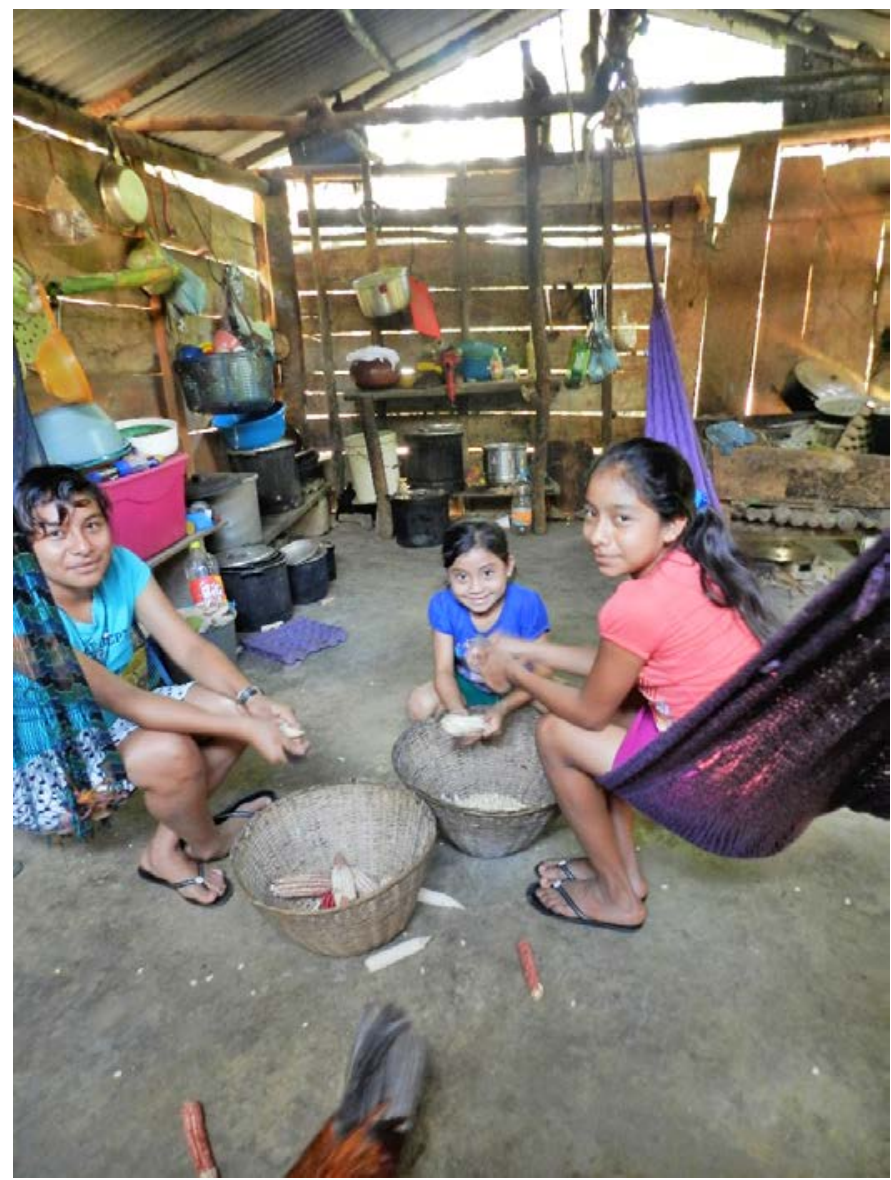

Figura 5. En la cocina, las hijas de Juan desgranan maíz para hacer tortillas y pozol (Fotografía de Adriana Corroy, 2017). 
En Masojá Grande, la hija menor de Miguel tiene otra posibilidad, ella quiere salir a estudiar medicina para trabajar y "modernizarse". No sucedió así con la mayor, quien se fue de la comunidad a raíz de la guerra de baja intensidad en 1995, y regresó casada con un indígena oaxaqueño. Hoy día, vive en Masojá Grande con sus hijos, en la casa de sus padres, mientras su esposo trabaja como mesero en Cancún, desde donde les envía dinero. Miguel tiene conflictos con algunos miembros de la localidad porque su yerno es foráneo y presionan a su hija para que se vaya del pueblo, como nos comentó la propia Lety en una entrevista: "la gente piensa que mi esposo puede heredar la tierra de mi padre al no tener en el pueblo a sus hijos varones".

En las familias ch'oles, anteriormente no dejaban a las hijas casarse con jóvenes foráneos para evitar conflictos por la tierra entre comunidades. Posteriormente, esta regla se flexibilizó y se permitía que el joven foráneo estuviera únicamente por tres meses en la localidad, en la casa de los suegros, y después, al conseguir su parcela, debía regresar a su localidad de origen con su mujer, hijas e hijos (Pérez, 1988). Estos cambios relacionados con la búsqueda de parejas externas a las comunidades de origen generan conflictos por la tierra entre padres e hijos, que son magnificados por la presión social de la comunidad en torno a la tierra.

Lo anterior nos habla de otra transformación de los ch'oles, en su relación con la tierra, su actividad laboral y la separación entre padres e hijos al interior de las familias, ya que las relaciones trastocadas por cambios, que no son únicamente geográficos e históricos, implican modificaciones individuales e intrafamiliares que están generando, además, un desfase temporal entre una generación y otra. Ante la emigración de los hijos, los padres tienden a buscar estrategias que soporten estas modificaciones, desplegando sus capitales con los hijos menores. Surgen conflictos individuales e intersubjetivos que confrontan su tradición con otras actividades a las que ahora se dedican sus hijos. Para los hijos que se van, la tierra ya no tiene el mismo valor simbólico y, por si fuera poco, se enfrentan a otros conflictos que también los confrontan con sus tradiciones, como los cambios en las relaciones laborales y el emparejamiento.

El habitus, a decir Bourdieu y Wacquant (1995), no es el destino, como se le interpreta a veces, siendo producto de la historia y de la trayectoria de vida; es, más bien, "un sistema abierto de disposiciones que se confronta permanentemente con experiencias nuevas y, por lo mismo, es afectado también permanentemente por ellas. Es duradero, pero no inmutable" (Bourdieu y Wacquant, 1995: 83). Podemos observar, a partir de estas experiencias, varias confrontaciones, así como la existencia de diferentes estrategias intrafamiliares para manejar las tensiones entre padres y madres con las hijas e hijos en relación con la migración de estos últimos y la tierra. 


\section{Cambios en el valor de la tierra en las relaciones entre padres e hijos ante la migración de los últimos}

1. La migración definitiva de los hijos. Juan, como padre, perdió el poder sobre el hijo que emigra y modifica su habitus; ahora invierte sus capitales sobre los hijos menores de edad que permanecen en su localidad. Ellos tienen más posibilidades de heredar la tierra y aumentar su capital simbólico; en esta etapa ya son menos los integrantes en la familia, entre menos hijos, más tierra. Los hijos que no regresaron renunciaron de manera obligada o deliberada a la tierra y a todo lo simbólico que representa; con la separación definitiva, se rompió el vínculo intrafamiliar y el vínculo con la tierra.

2. Migración esporádica de los hijos. Los hijos emigrantes de Juan regresan esporádicamente para mantener el vínculo familiar. Algunas veces envían dinero (capital económico) a sus padres, poco, y no les alcanza, como mencionó Juan en su narrativa. En estos casos, observamos que existe una esperanza de los padres y las hijas e hijos de regresar y retomar el vínculo con la tierra, en un campo que parece ampliado por las posibilidades y las nostalgias.

3. Otros padres como Miguel tienen hijos que emigran y regresan. Observamos que algunos de los hijos e hijas no se adaptaron a las condiciones externas que les impone el nuevo lugar. Ante esto, el padre ejerce su poder nuevamente y establece condiciones a los que han vuelto, tales como trabajar nuevamente en la milpa hasta ganarse el derecho de heredar la tierra, participar en las actividades del hogar y habitar en la casa paterna.

4. La migración temporal de Juanito. Juan, como padre, obtiene ayuda temporal de su hijo Juanito. La emigración temporal de su hijo beneficia económicamente a la familia; Juan incrementa su capital económico y obtiene temporalmente la mano de obra en la milpa. Así, continúa manejando su poder y heredará su tierra a Juanito cuando éste regrese definitivamente.

Para Juanito, la migración temporal implica tener que negociar permanentemente las tensiones entre dos mundos, el de la tradición y el del mercado. Él trabaja por tres meses en Sonora, regresa a Teanijá, trabaja con su padre en la milpa y vuelve otra vez al campo en Sonora. Allí, el trabajo de Juanito y sus conocimientos tradicionales en el campo son una herramienta útil (capital social), ya que son empleados en otro campo de cultivo, el de espárragos, o en la pizca de uvas, como lo hace también Prudencio. Ambos trabajan como empleados temporales en empresas multinacionales y con productos de exportación, monocultivos de escala masiva dirigidos al mercado internacional.

Todo lo anterior apunta a que el conflicto entre padres e hijos por la tierra a partir de la migración y la actividad laboral confronta el trabajo natural de subsistencia familiar y solidaria con otros empleos, dirigidos a diferentes mercados de trabajo. Esto presenta, al interior de las familias participantes en la investigación, diferentes espacios de negociación. Desde los padres y madres, implica "ver" 
cómo se pierde o resignifica el capital simbólico asociado a la tierra. Los hijos transforman sus actividades laborales tradicionales en el campo, usándolas como herramientas en otras actividades agrícolas, o las modifican, dirigiéndolas a los sectores secundario o terciario.

El capital simbólico del que Juan es poseedor sigue siendo transmitido a los hijos menores en un mecanismo de transmisión intergeneracional; éste regresa si también regresan los jóvenes con otras experiencias que lo han modificado. Ante la emigración de todos los hijos, sin apoyo y mano de obra, los padres se ven obligados a obtener otras fuentes de ingreso económico, como el rentar su tierra para sembrar milpa o la engorda de ganado. Lo que implica la pérdida en cadena del valor de la tierra.

El valor simbólico de la tierra también se modifica. Para Juan, la tierra es algo más a lo que se aferra para no perder sus derechos, pero también constituye un espacio para no desestructurarse él como persona, su identidad está arraigada a la tierra. Es el lugar desde donde carga con su tradición y ve a sus hijos partir, es su territorio; ese lugar, que más allá de ser un espacio geográfico, es un espacio simbólico, un campo ampliado por la migración de sus hijos, es también el territorio donde se perciben, histórica y socialmente, las relaciones de dominación (Rubio, 2006: 10-49).

Los jóvenes que emigran definitivamente no valoran la tierra ni trabajar en la misma, ya que consideran que lo que hacen sus padres es un trabajo muy pesado, hecho que confronta a los padres intersubjetivamente, pues la tierra, su trabajo y toda su representación simbólica, son ignorados de manera obligada o deliberada por sus hijos. Con la migración, los hijos pierden su derecho a la tierra como propiedad y también se pierde o resignifica su relacionalidad con ella.

\section{Conclusiones}

La historia de los ch'oles nos muestra una serie de modificaciones y despojos que han fisurado su relación con la tierra. Ello se relaciona con el valor simbólico que este pueblo le ha otorgado y que se confronta con otros valores, como el de la propiedad privada. El ejido, como parte de este paradigma de propiedad, no ha podido por sí mismo solventar la autosuficiencia alimentaria de pueblos ch'oles como Teanijá y Masojá Grande. La propiedad resulta insuficiente para la subsistencia de las familias y expulsa — de alguna manera- a los jóvenes, quienes buscan otras opciones para sobrevivir a través de la migración.

Con la separación se genera un rompimiento intergeneracional entre padres e hijos de las familias ch'oles, que va en contra del enraizamiento de este pueblo con la tierra. La generación de padres como Juan y Miguel no emigraba, debido a su anclaje con la tierra, los derechos sobre la misma y la actividad laboral en el campo como medio de subsistencia. La tierra, para los de su generación, representa un capital simbólico, fuente de poder y prestigio en la comunidad, y ante su familia. 
Las relaciones entre padres e hijos se ven afectadas por los cambios relacionados con la migración y la actividad laboral, se contrapone el trabajo natural de subsistencia familiar y solidaria con otros dirigidos a diferentes mercados. La migración actúa como un mecanismo de autorregulación al interior de la familia. Con las modificaciones en la relación entre padres e hijos, la migración se revela como un síntoma que nos permite observar la persistencia de mecanismos de reproducción social muy antiguos, como la explotación laboral y la separación familiar por la búsqueda de un trabajo asalariado.

Observamos, además, conflictos intersubjetivos en los padres y madres ante la indiferencia de algunos hijos, para los que la tierra ya no tiene un valor económico ni simbólico, pues resulta insuficiente para solventar sus necesidades de subsistencia y pertenencia. La familia es un espacio social de negociación permanente donde se lucha para mantener la tierra en su interior. La figura del padre estaba enraizada en la tierra, pero ahora lo está cada vez menos; la lucha actual es para no perderla. Despojados de la tierra, los milperos están perdiendo su única fuente identitaria: ¿si ya no luchan por la tierra, por qué van a luchar? ¿Si ya no luchan por ser milperos, qué son?

La migración entre los ch'oles es un fenómeno natural y naturalizado, con sus pros y sus contras; es una decisión libre o forzada que obliga a los que la experimentan a modificar sus relaciones sociales. En el caso de la familia, los obliga a modificar los roles intrafamiliares y la distribución de su capital simbólico, uno donde la tierra ya no tiene el mismo valor.

\section{Agradecimientos}

Este trabajo de investigación fue enriquecido con los valiosos comentarios del doctor Charles S. Ckeck, mi director de tesis y con el apoyo y guía de mi comité conformado por los doctores Elisa Cruz Rueda, Laura Huicochea Gómez y Juan Jesús Vázquez Álvarez.

\section{Bibliografía}

Aguilar Jiménez, Carlos Ernesto

2014 La agricultura sostenible en el valle de Tulijá, Chiapas, México. Tuxtla Gutiérrez: Universidad Autónoma de Chiapas.

Alejos García, José

1995 "Los choles en el siglo del café. Estructura agraria y etnicidad en la cuenca del río Tulijá”, Chiapas, los rumbos de otra historia, pp. 319-328, Juan Pedro Viqueira y Mario H. Ruz (eds.). México: Universidad Nacional Autónoma de México, Instituto de Investigaciones Filológicas, Coordinación de Humanidades, Centro de Estudios Mayas, Universidad de Guadalajara, Centro de 
Investigaciones y Estudios Superiores en Antropología Social, Centro de Estudios Mexicanos y Centroamericanos.

1999 "Vencer o morir: mitología y sociedad entre los choles", Estudios de Cultura Maya, XX: 428-441. DOI: https://doi.org/10.19130/iifl.ecm.199-20.460.

Alejos García José y Nancy Elizabeth Martínez Sánchez

2007 Ch'oles, pueblos indígenas del México contemporáneo. México: Comisión Nacional para el Desarrollo de los Pueblos Indígenas, <https://www.gob.mx/ cms/uploads/attachment/file/11016/choles.pdf > [consultada el 9 de enero del 2019].

Andrade García, David Nicolás

2015 “La llegada del 'progreso': fincas y capital extranjero en la configuración del territorio ch'ol de 1870 a 1949”, tesis de maestría en Desarrollo Rural Regional. San Cristóbal de Las Casas: Universidad Autónoma de Chapingo.

Arriola, Joaquín

2002 "Propiedad y Poder", VIII Jornadas de Economía Crítica. Valladolid: Universidad de Valladolid, <http://webs.ucm.es/info/ec/jec8/Datos/documentos/comunicaciones/Fundamentos/Arriola\%20Joaquin.PDF> [consultado el 18 de diciembre del 2018].

Blanco, Mercedes

2011 "Investigación narrativa: una forma de generar conocimientos", Argumentos, 24 (67): 135-156.

Bourdieu, Pierre

2011 Las estrategias de reproducción social. Argentina: Siglo XXI Editores.

Bourdieu, Pierre y Loïc J. D. Wacquant

1995 Respuestas por una antropología reflexiva. México: Grijalbo.

Breton, Alain

1988 "En los confines de norte chiapaneco, una región llamada 'bulijib'. Itinerario y enseñanzas de una visita en el 'pais chol' (1737-1738) y otros textos", Estudios de Cultura Maya, XVII: 295-354. DOI: https://doi.org/10.19130/iifl. ecm.1988.17.602.

Carton de Grammont, Hubert

2009 "La desagrarización del campo mexicano", Convergencia. Revista de Ciencias Sociales, 50: 13-55.

Constitución Mexicana

1917 Diario Oficial de la Federación: 1-43. México, <http://www.ordenjuridico.gob. $\mathrm{mx} /$ Constitucion/1917.pdf $>$ [consultada el 7 de diciembre del 2018].

Creswell, John

1994 Research Design: Qualitative, Quantitative, and Mixed Method Approaches. Los Ángeles: Sage Publications. 
Creswell, John

2005 Educational research: Planning, conducting, and evaluating quantitative and qualitative research. Upper Saddle River: Pearson Education.

De Vos, Jan

1984 "Una legislación de graves consecuencias. El acaparamiento de tierras baldías en México, con el pretexto de la colonización, 1821 a 1910”, Historia Mexicana, 34 (1): 76-113.

2010 Fray Pedro Lorenzo de la Nada, misionero de Chiapas y Tabasco. México: Fondo de Cultura Económica.

Denzin Norman K. e Ivonna S. Lincoln

2011 La investigación cualitativa como disciplina y como práctica. España: Gedisa.

Diario Oficial de la Federación

1969 “Dotación ejidal de Salto de Agua 1954-1969". Chiapas, México, pp. 9-10.

1973 “Dotación, ampliación y negación de ejidos de Tila, 1934-1973”. Chiapas, México, pp. 24-26.

Gall, Olivia

1999 “Racismo, modernidad y legalidad en Chiapas”, Dimensión Antropológica, XV: 55-86.

García de León, Antonio

1979 "Algunas consideraciones sobre los choles", Estudios de Cultura Maya, XII: 257-284. DOI: https://doi.org/10.19130/iifl.ecm.1979.12.530.

Grosfoguel, Ramón

2013 "Racismo/sexismo epistémico. Universalidades occidentalizadas y los cuatro genocidios/epistemicidios del largo siglo xvı", Tabula Rasa, 19: 31-58.

Guerrero Galván, Luis René

2016 "A propósito del aniversario porfiriano. Una aproximación acerca de las compañías deslindadoras en tiempos del Porfiriato", Revista Latinoamericana de Derecho Social, 22: 329-342. DOI:10.1016/j.rlds.2016.03.

Gutiérrez Sánchez, Javier

2017 “'Ser joven' en distintos contextos ch'oles del norte de Chiapas”, Estudios de Cultura Maya, L: 299-322. DOI: https://doi.org/10.19130/iifl.ecm.2017.50.814.

Haraway, Donna

1988 "Situated Knowledges: The Science Question in Feminism and the Privilege of Partial Perspective”, Feminist Studies, 14 (3): 575-599.

Harvey, David

2005 "El nuevo imperialismo: acumulación por desposesión", Socialist Register 2004: 99-129. 
Hernández Xolocotzi, Efraim, Eduardo Bello Baltazar y Samuel Levy Tacher

1995 La milpa en Yucatán. Un sistema de producción agrícola tradicional. Texcoco: Colegio de Postgraduados.

Imberton Deneke, Gracia

2002 La verguienza: enfermedad y conflicto en una región chol. México: Universidad Nacional Autónoma de México, Prolmmse.

Instituto Nacional de Lenguas Indígenas (INALI)

2008 Ley General de Derechos Lingüísticos de los Pueblos Indígenas: 31-112. México, $<$ https://www.inali.gob.mx/pdf/CLIN_completo.pdf> [consultada el 4 de febrero del 2018].

Josserand, Kathryn y Nicholas Hopkins

2006 "Lenguaje ritual chol", Fundación para el Avance de los Estudios Iberoamericanos, <http://www.famsi.org/reports/94017es/index.html> [consultada el 23 de febrero del 2018].

Kourí, Emilio

2015 "La reinvención del ejido", Nexos, <https://www.nexos.com.mx/?p=23778> [consultado el 13 de enero del 2018].

López Arévalo, Jorge y Óscar Peláez

2013 "Globalización neoliberal, mercado de trabajo y emigración en Chiapas", Buscando el norte. Declive económico y emigración en la Región Sierra de Chiapas, p. 22, Jorge López Arévalo y Jorge Peláez (eds.). Universidad Autónoma de Chiapas.

Merino Acuña, Roger

2014 "Descolonizando los derechos de propiedad, derechos indígenas comunales y el paradigama de la propiedad privada", Boletin Mexicano de Derecho Comparado, XLVII (141): 935-964.

Mignolo, Walter

2000 Historias locales/diseños globales. Colonialidad, conocimientos subalternos y pensamiento fronterizo. Madrid: Akal.

Pérez Chacón, José

1988 Los choles de Tila y su mundo. Tuxtla Gutiérrez: Gobierno del Estado de Chiapas, Subsecretaría de Asuntos Indígenas.

Quijano, Aníbal

1993 "Colonialidad del poder, eurocentrismo y América Latina”, La colonialidad del saber: eurocentrismo y ciencias sociales. Perspectivas latinoamericanas, pp. 203-242, Edgardo Lander (comp.). Buenos Aires: Consejo Latinoamericano de Ciencias Sociales.

Rubio, Blanco

2006 “Territorio y globalización en México: ¿un nuevo paradigma rural?”, Comercio exterior, 56 (12): 1047-1054. 
Schongut Grollmus, Nicolas

2015 "Perspectiva narrativa e investigación feminista: posibilidades y desafíos metodológicos”, Psicología, Conocimiento y Sociedad, 5 (1): 110-148.

Secretaría de Desarrollo Social (SEDESOL)

2010a "Resumen Municipal del Municipio de Salto de Agua", <http://www. microrregiones.gob.mx/catloc/Default.aspx?tipo $=$ clave $\&$ campo $=$ mun\&val or $=07>$ [consultada el 3 de noviembre del 2018].

2010b "Resumen Municipal del Municipio de Tila", <http:/www.microrregiones.gob. $\mathrm{mx} /$ catloc/LocdeMun. aspx $?$ tipo $=$ clave $\&$ campo $=$ loc\&ent $=07 \&$ mun $=096>$ [consultada el 15 de noviembre de 2018].

Toledo Tello, Sonia

2013 "De peones de fincas a campesinos. Transformaciones agrarias y domésticas en el norte de Chiapas (siglos xx y xxI)", Entre Diversidades. Revista de Ciencias Sociales y Humanidades, 1: 13-41. DOI: https://doi.org/10.31644/ED.1.2013.a01.

Villafuerte Solís, Daniel

2015 “Crisis rural, pobreza y hambre en Chiapas”, LiminaR, 13 (1): 13-28.

Viqueira, Juan Pedro

2011 "Indios y ladinos, arraigados y migrantes en Chiapas: Un esbozo de historia demográfica de larga duración”, Caras y máscaras del México étnico. La participación indígena en las formaciones del Estado Mexicano, pp. 1-61, Roth Seneff (ed.). México: El Colegio de México, Centro de Estudios Históricos.

Warman, Arturo

2003 "La Reforma Agraria mexicana: una visión de largo plazo”, Reforma agraria. Colonización y cooperativa, pp. 84-95. México: Registro Agrario Nacional.

Adriana Corroy Moral. Mexicana. Licenciada en Biología por la Universidad Juárez Autónoma de Tabasco, maestra en Educación Ambiental por la Universidad de Guadalajara, cursa el doctorado en Ecología y Desarrollo Sustentable en El Colegio de la Frontera Sur (ecosur), Unidad San Cristóbal de Las Casas, Chiapas. Actualmente desarrolla el proyecto de investigación "Conflictos microsociales de familias ch'oles en Tila y Salto de Agua, Chiapas”. Entre sus publicaciones se encuentran: "El ambiente desde la educación ambiental, algunas aproximaciones teóricas" y "Educación ambiental para el desarrollo sustentable de comunidades indígenas chontales", la primera como autora única, la segunda en coautoría.

adcorroy@ecosur.edu.mx

adriana.corroy@yahoo.com.mx 